\title{
ONSUMERS' OPINIONS ON GENDER STEREOTYPING IN ADVERTISING
}

\author{
By Petra Kolman
}

Ana Tkalac Verčič ${ }^{2}$

Successful advertising conveys dominant and accepted values of a certain country, culture or group of people. By using values characteristic of a specific segment, the likelihood of creating a successful advertisement increases, which is why stereotypes that exist in a society have a very big influence on advertising content and style. One of the most discussed types of stereotyping is gender stereotyping. Since a culture greatly affects the way gender roles are defined and since most of the conducted research in this area comes from the western world, this study was aimed at exploring the way gender roles are perceived in Croatia.
The main goal of the study was to get insight into the way Croatian consumers perceive advertising stereotypes. The theoretical framework was based on Hofstede's masculinity dimension according to which Croatia is a conservative country with traditional values. Through the research it came out that respondents recognized various elements of gender stereotyping such as age, work roles, objectification and the gender of the voiceover. In most cases female respondents recognized gender roles in advertising as negative and stated negative attitudes towards them. On the other hand male respondents recognized mentioned stereotypes but were mainly indifferent to them.

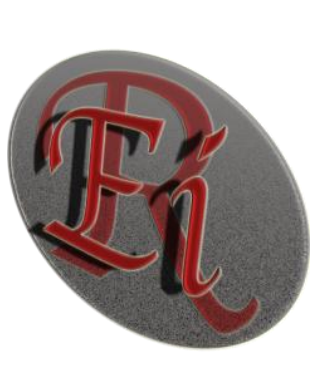

\section{Keywords:}

Advertising

Hofstedes

masculinity

dimension

Gender

stereotyping

Consumers

percepcion

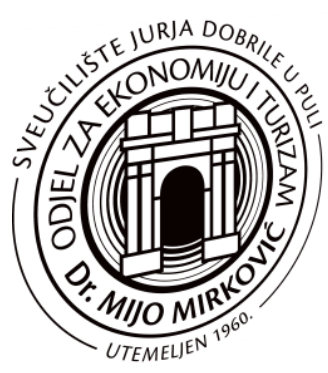

\footnotetext{
1 Šmidhenova 1110430 Samobor, Telephone: +38598 9462705, E-mail: petraki20@yahoo.com

${ }^{2}$ Faculty of Economics \& Business, Associate Professor, Trg J. F. Kennedya 6, 10000 Zagreb Telephone: +3851238 3333, Email: atkalac@efzg.hr
} 


\section{INTRODUCTION}

Using female sources of communication in advertising has motivated heated debates of the way women are depicted in advertisements, and raised the question of whether this representation is reflective of women's role in society (Lin, 2008, 409). By showing women as decorative, sexual objects, usually younger than men (Hovland, McMahan, Lee, Hwang and Kim, 2005, 887), advertisers believe they can create situations that consumers can identify with. This potential misrepresentation of women is important since research shows that representation of gender roles in advertising has a significant impact on thought patterns in society (Khairullah and Khairullah, 2009, 58) On the other hand, advertising specialists stress that relationships presented in advertising are only a reflection of relationships that already exist in societies. Even though certain attitudes and ideas are under- of over-represented, or occasionally accentuated and embellished, they still only reflect realities of a certain society or culture (Linder, 2002, 490). This raises the following question - what are the preferred gender roles in advertising? Are they in line with the traditional perception of women and men, or is there a newer way of dividing male and female roles.

These questions can only be answered within a context of a specific culture. Since every society (and every culture) has its particular norms, the question of gender representation in advertising is a very culturally specific one. The number of cross-cultural studies, on this topic, is relatively small, and most of them have been conducted in western countries (Zhang, Srisupandit and Cartwright, 2009, 683) while none have (so far) been carried out in Croatia.

\section{LITERATURE REVIEW}

\section{A. Gender stereotypes in advertising}

Advertising reflects society, conveying dominant and accepted values of a certain country, culture or group of people. It is based on the assumption that members of a culture, subculture or marketing segment think and behave in a specific, predictive way (Markin, 2006, 181). By using values characteristic of a certain segment, the likelihood of creating a successful advertisement, increases (Mayne, 2000, 56). This is why stereotypes that exist in a society have a very big influence on advertising content and style.

Stereotypes and prejudices exist and are an inevitable part of our surroundings. Stereotypes can be defined as socially shared sets of values about attributes characteristic for members of a specific social category (Greenwald and Banaji, 1995, 4). Gender roles in a society shape stereotypes and are reflected in advertisements that depict real life. Researchers are interested in analyzing advertisements, both, to explore the stereotypes that are reflected in advertising and to maximize advertising success.

There is a multitude of studies that were aimed at exploring the way men and women are portrayed in advertising and if genders are shown as equal or not. Most of those studies point to a conclusion that women are described as sexual objects and passive participants, while positive characteristics of males are over-implied (Soley and Kurzbard, 1986, 46; Ferguson, Kreshel and Tinkahm, 1990, 40; Klassen, Jasper and Schwartz, 1993, 30). Jones (1991, 231) offered an overview of most common gender stereotypes in advertising, that include elements like ranking (men are portrayed as executives), size (men are described as bigger and stronger), subordination (women are shown in positions of submission), touch (women are often touching various surfaces) and family dynamics (women are the center of family life and are more connected to daughters then sons). Eumham and $\operatorname{Mak}(1999,413)$ conclude that age and physical appearance are the areas in which stereotyping is most common. Mentioned authors state that women are presented as 
younger and very beautiful, primarily because of their decorative role. They also add that men are commonly the ones that give the main message of an advertisement. This is primarily because in most cultures people tend to have more faith in men than women.

A big difference between the way men and women are presented can be found in how working roles are portrayed. Generally, men are shown to be working, and are described as professionals and experts. On the other side, women are shown to be in non-working roles and if they are in a work-role, they are most commonly presented as employees (An and Kim, 2006, 181). This situation is nothing new and is documented in studies almost forty years old. Courtney and Lockeretz (1971, according to Odekerken-Schröder, De Wulf and Hofstee, 2002, 408) name types of work roles in advertising that all "belong" to men: top level managers, people from the entertainment industry and professional athletes, while women are mid-level mangers and white collar workers.

Some authors like Gamman and Makinen $(1994,50)$ suggest that women are used to being perceived as sexual objects. In most cases women are shown as objects in advertisements that promote cosmetic products, tobacco and alcohol. It needs to be acknowledged that the level of objectifying male roles in advertisements is also increasing. Another aspect of stereotyping is shown through the setting in which men and women are presented. Women are mostly shown in the home, with children and doing housework, while men are shown outside the home, being active (Eumham and Mak, 1999, 413).

All of the described stereotypes represent beliefs that exist all over the world, but it is important to remember that stereotypes (just as gender roles) are culturally specific and that any findings in this area should not be generalized extensively. The way in which gender roles are portrayed depends mostly on the norms characteristic for a certain group of people, and this in turn influences the success of an advertisement. It is clear that in shaping and analyzing advertising messages, experts need to be familiar with cultural dimensions of a society.

\section{B. Hofstede's cultural dimensions and stereotypes in advertising}

Among various attempts of discovering and empirically testing variations in culture, Geert Hofstede studied the interactions between national cultures and organizational cultures. He offered a five-dimensional model that deals (among other things) with norms governing societal roles of men and women (An and Kim, 2006, 181). In his research Hofstede discovered a fourdimensional structure on which societies differ; those dimensions included power distance, individualism, uncertainty avoidance and masculinity (a fifth dimension, long term orientation, was added later) (Hofstede, 2001, 101). Among five mentioned dimensions, masculinity is connected to societal norms that determine the roles of men and women. In Hofstede's opinion the perception of gender role differentiation is a factor on which different cultures can be compared (An and Kim, 2006, 181).

Even though Hofstede did not categorize Croatia in his research (at least not as a country excluded from Yugoslavia), close historic roots allow certain conclusions based on existing data (Tavakoli, Keenan and Crnjak-Karanovic, 2003, 49). In his later analyses (based on a reanalysis of IBM data) he calculated that the masculinity index for Croatia is 40 , which is relatively low (Hofstede, 2001, 101). Croatian authors (Bahtijarević-Šiber, Sikavica, and Pološki Vokić, 2008, 176) also mention results (show in graph 1) which demonstrate the difference in the masculinity dimension among several countries. It is visible from graph 1 that Croatia is positioned quite low on the masculinity dimension. However, this research that was an approximation of results collected in former Yugoslavia doesn't seem to represent the type of society Croatia is today. 
When comparing "male" and "female" societies, male societies are the ones in which there is a high level of competitiveness, interest in material gain, assertiveness, independence, success, promotion, orientation towards action. On the other side female societies are the ones in which there is a high level of interest in cooperation, maintaining good relationships, taking care of others, solidarity, higher quality of life and similar. The description of both types of society seems to point towards the fact that Croatia is more of a masculine then feminine culture. Even though determining the position Croatian society has in Hofstede's classification has significant methodological limitations it is still interesting to view the research on gender stereotypes through this particular lens.

\section{FIGURE 1. THE DIFFERENCE IN THE MASCULINITY AMONG SEVERAL COUNTRIES}

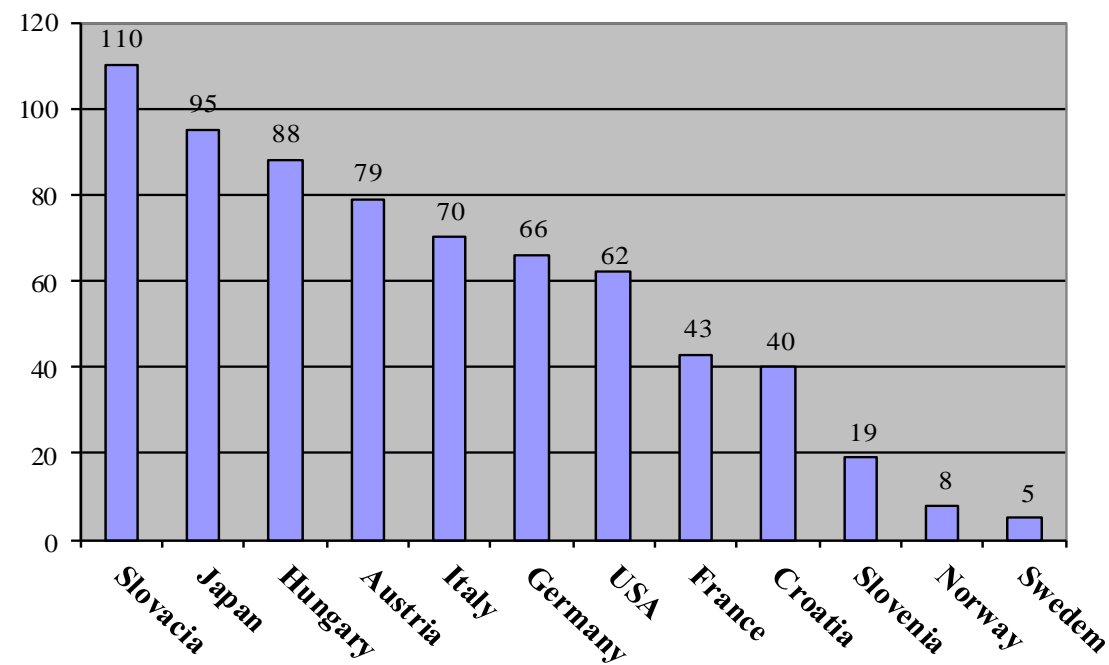

Source: Bahtijarević - Šiber, Sikavica and Pološki Vokić, 2008

In feminine cultures there are smaller differences among genders in the way roles are perceived, which means that men are more inclined to assume jobs such as housework (which in male cultures is perceived as a typically female job). However, even in feminine cultures, in advertisement, men are shown in roles of higher importance (Mooji, 1998, 88). In other words, regardless of the level of masculinity a society has, men are depicted as more important (even though, differences are more pronounced in masculine cultures).

A group of authors (Odekerken-Schröder, De Wulf and Hofstee, 2002, 408) explored if gender stereotyping is more pronounced in masculine countries. In their study they analyzed advertisements in various magazines from the United Kingdom and Holland. Their analysis was based on Hofstede's classification in which United Kingdom was categorized as a masculine society, while Holland was categorized as a feminine society. The criteria for recognizing a stereotype in an advertisement was the gender of the main character, his or her age, type of role they have (working or non- working), type of working role (top managers, entertainers, professional athletes etc.), type of non-working roles (family, recreation or decorative), stereotyping of the main female character (sexual object, equal to the male characters, etc.) and type of dress (shy or seductive). Results showed that advertisements in the feminine culture 
depicted women in working roles more often than in the masculine culture. On the other hand in masculine cultures women are shown as significantly younger than men and more of a sexual object.

An and Kim $(2006,185)$ also used Hofstede's dimensions to explore cross-cultural differences in internet advertising in the USA (as a masculine culture) and Korea (as a feminine culture). They analyzed the content of 400 advertisements and found out that a greater percentage of Korean ads featured women as a main character, and portrayed them in recreational and family roles.

Since it is obvious that a culture greatly influences the way gender roles are defined, and since most of the conducted research in this area comes from the western world, this study was aimed at exploring the way gender roles are perceived in Croatia. The main goal of the study was to get insight into the way Croatian consumers perceive advertising stereotypes. The main research question of the study was - Is there a difference in male and female perception of gender stereotyping in advertising, among Croatian consumers?

\section{RESEARCH METHODOLOGY}

Since this type of problem has not been studied among Croatian consumers, the study was shaped and conducted as an exploratory study. The main method of data collection chosen to answer the research question was a focus group approach. This method was selected because the goal of the study was to get a deeper insight into the way Croatian consumers perceive potential stereotypes in advertisements. In other words, it was important and in line with the study's main goal to allow respondents to feel relaxed and because of that freely express their opinions through a constructive discussion.

The focus groups were organized in three stages. During the first stage of the focus group interviews, respondents participated in a general discussion on the topic of gender stereotyping. In the second part they were shown a series of ten selected advertisements. Four of those advertisements were about male products, four were about female products and two were about gender neutral products (categorized according to likelihood and frequency of use, based on the methodology by Leung $(1995,111)$ ). Female products included products such as personal hygiene and care products, clothes, jewelry, cleaning products and household products. Male products included internet, technology, cars, insurance and financial services, sport and alcohol, etc. Neutral products included food, juices, travel, restaurants and stores, entertainment, transport and medicine.

After each of the advertisements there was a brief discussion on the topic that then evolved towards general issues of stereotyping in advertisements. The focus group interview lasted between 60 and 75 minutes and was recorded in full.

One of the main disadvantages of a focus group is the fact that the data obtained from the group(s) is not necessarily representative of the whole population. In order to minimize this problem, three separate interviews were conducted, each with a purposive sample of 10 respondents. Judgmental sampling or purposive sampling in this study meant that the researcher chose the sample based on who she thought would be appropriate for the study.

In order to get an even better insight into the problem, focus groups were followed by ten indepth interviews. Respondents for this part of the study were also chosen by judgmental sampling. Among the 40 respondents that participated in both stages of the study, 20 were female and 20 were male. 


\section{RESULTS}

It became clear very early in the discussion that there are some very big differences among male and female respondents in the way they perceive gender stereotyping. Male respondents described men (in general) as competent, strong, active, and oriented towards useful things. Female respondents described men (in general) as authoritative, active, sometimes aggressive, physically stronger, and protective. Stereotypes that all the respondents agreed upon included men being perceived as ruthless, hasty, clumsy, careless, less oriented towards details, more oriented towards thinking about sex, interested in sports and making money. Most of the participants agreed that men are perceived as dominant and father figures.

When describing women, mail respondents were quite unison, they were perceived as weaker, gentle, emotional, hard to understand and disloyal. Women described their own gender as emotionally stronger than men, loyal to their families and very easy to understand. Stereotypes that all respondents recognized as dominant for the female gender included beauty (but also a lack of intelligence), dependency on men, need for protection, communicativeness, good relationship with children and being good at housework. According to both male and female respondents, women are mostly perceived as mothers and housewives.

When asked about gender roles, most respondents agree on what they are. They mostly believe gender roles are based on tradition and they don't believe they are about to change. Three respondents suggested that this type of gender division is normal because it is based on religion, while six (female) respondents think that women shouldn't complain since they brought the problem on themselves. Younger respondents with higher levels of educations believe that gender roles are evolving and that Croatia is slowly following the example of countries like Sweden.

After viewing 10 selected advertisements ( 4 for male, 4 for female and 2 for neutral products) most respondents agreed that advertisements were unrealistic and sometimes even offensive. The biggest detected issue was the fact that both sexes were portrayed as objects which respondents perceived as degrading. Sex appeal used in ads was perceived as rude by five female respondents and therefore should be banned, while male respondents stated that they don't mind it. Also the main character's age is perceived in various ways. Female respondents have negative attitudes towards the growing trend of only using very young and beautiful women, while men in the ads are middle aged. Male respondents didn't mind the age of the characters in the advertisements (male or female) and some even stated that the previously mentioned trend is normal since men are in their prime when they reach middle age, while women are in their prime in their twenties.

Female respondents didn't appreciate depicting women in the ads as less capable or the fact that only men give advice on how to use a product (especially if it's a traditionally female product). Men were indifferent to this. As for the background of an ad, most of the respondents agreed that it is a lot more common to see a women surrounded by children then men (in an ad), but most of the respondents didn't mind this fact. If women are shown in the home they tend to be older, while younger women have a tendency to be shown outside the home. Men are often engaged in a sports activity, while younger women are shown socializing with friends. All of the respondents agree with this analysis and didn't state any negative attitudes toward it. When asked who they trust more in giving the final message of the ad, both genders stated that they have a bigger level of trust in male characters (even though women stated that they are slightly unhappy with this fact). Men stated that they tend to believe male voices more because they are pleasant and have a higher level of expertise. 
When asked how an advertisement affects their buying decision seven male and four female respondents stated that ads have no influence on them. Others indicated that they are influenced by advertisements. This second group stated that if they don't like the ad or if they perceive it as insulting, there is a big likelihood that they won't buy the advertised product.

The question on the affect of a stereotyped advertisement raised a big discussion. Most of the respondents had a conflicting opinion on this issue. On one side they stated that advertisements with stereotyped content are offensive and cause a negative attitude, but on the other side when talking about specific situations they mostly stated that they like ads that depict women as housewives. Younger respondents with higher education levels had the most negative attitudes towards this type of stereotyping and stated that it can cause negative attitudes towards the product in the add.

The respondents mostly agreed that there is a very strong influence of advertisements (especially TV ads) on how young people's attitudes are shaped. Four older respondents feel that advertisements are a good way of shaping gender and other roles, while most of the younger respondents don't agree since they feel ads promote unrealistic beauty and unfair gender stereotypes (for example women as less capable then men). Younger respondents also believe objectification can be dangerous for shaping young people's frames of reference (they gave the example of the Axe advertisement in which the message is - that just by using a product, men can become extremely sexually attractive to women).

\section{DISCUSSION}

This study pointed towards some initial insights as to how gender stereotypes are perceived in Croatian society. The respondents included in the study showed a high level of awareness of gender stereotypes. The difference in perception of mentioned stereotypes was significant and it seemed that both men and women are less objective to their own gender. However, almost all respondents agreed that in Croatian society men are perceived as authoritarian and capable, while women are perceived as submissive and very emotional.

Generally, older respondents perceive gender roles portrayed in ads as acceptable while younger respondents mostly don't agree and think it is time to minimize the difference between the portrayal of men and women. In other words older respondents have a much more positive attitude towards the described division of roles. As for the difference between genders, men seem to have less of an objection towards gender stereotyping and seem to have a more positive attitude towards the way genders are portrayed in advertisements.

Both male and female respondents agreed that showing male of female bodies as an object is not a good way of creating messages in ads. This type of presentation of male and female bodies and application of the "sex sells" principle is viewed negatively by all respondents. However, once again the attitude that women stated towards this type of representation is more negative than the one stated by men. The age of characters in ads seems to cause big reactions since women tend to believe that this is an important area of stereotyping. Also, the approach that depicts women as less capable caused very negative reactions in female respondents who stated that they see this as insulting. As for the male respondent their opinion varied. Younger respondents stated that this type of stereotyping is unrealistic while older subjects don't agree. All of the male respondent, irrespective of their age, showed very little interest in this gender division and were neutral towards it. The gender of the voice-over in the advertisement also raised a heated debate among the respondents. Men seem to trust a male voice far more than a female voice, while women disagree. 
This study was an exploratory study with an aim to get some initial insight into how male and female viewers in Croatian society perceive gender role stereotyping. It is difficult to draw any definite conclusions on general attitudes and values, but there seem to be two main trends. Age and gender affect the way stereotyping is perceived. Younger respondents have a negative view of stereotyping and don't seem to see gender roles in such a traditional and definite way. Also men seem more inclined to accept traditional role division and have less of a problem with stereotyping.

Advertising is shaped and created on the bases of various expectations, values and beliefs of members of a certain culture. It represents and reflects a set of cultural values characteristic for specific products or consumers (An and Kim, 2006, 185). These types of beliefs include acceptable and expected behaviors characteristic for both genders called genders roles.

The main aim of this study was to try and get in introductory insight into the perception of Croatian consumers when gender roles and their representation in advertisements are concerned. The theoretical context in which the research was incorporated drew on Hofstede's dimension of masculinity. According to previously mentioned results Croatia belongs into the category of countries that have clearly delineated gender roles. Croatian society, being relatively traditional, conservative and influenced by the dominant religion (catholic) is still very clear on what male and female roles are.

The results of the study are in line with results of certain previous researchers (Morrison and Shaffer, 2003, 265) and confirm the assumption that in male type of societies there are very prominent differences in the perception of gender roles, depending on the gender of the viewer. Female respondents (both in previous and this study) have very negative views on gender stereotyping while male respondents have mostly neutral attitudes towards this issue. This study also showed that age had a big impact on the way gender stereotyping was perceived, meaning that older respondents see this gender division as necessary and good, while younger respondents believe it is unacceptable and should not be accepted.

One of the most problematic areas that emerged was the approach of showing women as less capable and as sexual objects. According to Odekerken-Schröder, De Wulf and Hofstee (2002, 408) women are depicted as inferior and incapable, while men are shown as authoritative and competent. It is not surprising that female respondents didn't appreciate this type of stereotyping. They expressed their dissatisfaction and stated that they see those roles as unrealistic and offensive and consequently a source of negative attitudes. Younger male respondents had a relatively neutral attitude towards mentioned stereotypes, while older male respondents stated that these roles are realistic to a certain extent. It is interesting that male respondents of all ages didn't even notice that this is a stereotype until they were warned. As for the process of objectification, according to Monk - Turner et al. $(2008,201)$ this process refers to usage of human body and sex to induce sales (while the body shown in such an advertisement has only a decorative purpose). Even though women are objectified a lot more than men, male bodies are also occasionally being used only as $s$ decoration. Both male and female respondents perceived objectification as bad, but not in the same extent. Women had mostly negative opinions and stated this type of communication should be banned. Men on the other hand were mostly indifferent. Odekerken-Schröder, De Wulf and Hofstee $(2002,408)$ made an interesting conclusion, namely the amount of objectification is the same in both, feminine and masculine societies.

Based on described results, it is possible to conclude that, like in previous studies on this topic (An and Kim, 2006, 185; Odekerken-Schröder, De Wulf and Hofstee, 2002, 408; Valls-Fernández and Martínez, 2007, 691) advertising reflects the society it is created in. In masculine cultures tradition comes first, men are authoritarian and dominant, people are conservative and there is a 
significant influence of the dominant religion. For advertisers, that means that women are represented as housewives, centers of the family, mothers, and mostly less competent then men and often with a decorative role.

One of the main goals of this study was to get some insight into the way Croatian consumers perceive gender roles in advertising. This initial exploratory research offers information for marketing experts and advertisers as well as for further academic research. The study however has certain limitations that don't allow extensive generalization of results. The sample that included only 40 respondents is the most obvious one. Also, using only qualitative methodology as the approach to research, limits (to a certain extent) the possibility of generalization.

\section{CONCLUSION}

The main aim of this study was to find out more about the potential differences between Croatian male and female consumers in the way they perceive gender roles and stereotyping in advertising. The theoretical framework was based on Hofstede's masculinity dimension according to which Croatia is a conservative country with traditional values. In order to find out more about the described topic respondents were engaged in a constructive discussion through a series of focus groups and in-depth interviews.

Through the research it came out that respondents recognized various elements of gender stereotyping such as age, work roles, objectification and the gender of the over voice. In most cases female respondents recognized gender roles in advertising as negative and stated negative attitudes towards them. On the other hand male respondents recognized mentioned stereotypes but were mainly indifferent to them.

Mentioned results are in line with previous research in other countries. Respondents trust a male voice-over more and have a better general attitude towards advertisements that are based on various gender stereotypes. Advertising give a realistic insight into society and is a reflection of its norms and rules of behavior. Results of this study can be (to a certain) extent applied to other masculine societies, especially those close to Croatia. This however is only a first step in uncovering this issue and furthering the knowledge on gender stereotyping in advertising.

\section{REFERENCES}

An, D., Kim, S. (2006): Relating Hofstede's masculinity dimension to gender role portrayals in advertising - a cross cultural comparsion of web advertisements. International Marketing Review, Vol. 24, Iss. 2, pp.181 - 207.

Bahtijarevićc-Šiber, F., Sikavica, P., Pološki Vokić, N. (2008): Suvremeni menadžment, Školska knjiga, Zagreb

de Mooij, M. (1998): Masculinity/Femininity and consumer behavior. In Hofstede, G. (ed.) Masculinity and Femininity. The Taboo Dimension of National Cultures, Sage Publications

Eumham, A., Mak, T. (1999): Sex - role stereotyping in television commercials: a review and comparsion of fourteen studies done on five continents over 25 years. Sex Roles, Vol. 41, pp. 413 $-437$.

Ferguson, J., H., Kreshel, P., J., Tinkham, S., F. (1990): In the pages of Ms.: sex role portrayals of women in advertising, Journal of Advertising, Vol. 19, Iss. 1, pp. 40-51.

Gamman, L., Makinen, M. (1994): Female fetishism: A new look. Lawrence \& Wishart, London

Greenwald, A. G., Banaji, M. R. (1995): Implicit social cognition: Attitudes, self-esteem, and stereotypes, Psychological Review, Vol. 102, Iss. 1, pp. 4-27. 
Hofstede, G. (1993); Cultural constraints in management theories. Academy of Management Executive, Vol. 7, Iss. 1, pp. 81-94.

Hofstede, G. (2001), Culture's Consequences: Comparing Values, Behaviors, Institutions, and Organizations across Nations, Sage, Thousand Oaks, CA

Hovland, R., McMahan, C., Lee, G., Hwang, J., S., Kim, J. (2005): Gender role portrayals in American and Korean advertisements, Sex Roles, Vol. 53, pp. 887-899.

Jones, M. (1991): Gender stereotyping in advertisements. Teaching of Psychology, Vol.18, pp. 231 233.

Khairullah, D., H., Z., Khairullah, Z., Y. (2009): Cross-cultural analysis of gender roles: Indian and US advertisements, Asia Pacific Journal of Marketing and Logistics, Vol. 21, Iss. 1, pp. 58-75.

Klassen, M., Jasper, C., Schwartz, A. (1993): Men and Women: Images of Their Relationships in Magazine Advertisements. Journal of Advertising Research, Vol. 33, Iss. 2, pp. 30-39.

Leung, L. (1995): Appraising sex-role portrayal in Korean television commercials, Media Asia, Vol. 22, Iss. 2, pp. $111-6$.

Lin, C. (2008): Sexual Issues: The analysis of female role portrayal preferences in Taiwanese print ads, Journal of Business Ethics, Vol. 83, pp. 409-418.

Linder, K. (2002): Images of Women in general interest and fashion magazine advertisements from 1955 to 2002, Sex Roles, Vol. 51, pp. 490-421.

Mayne, I. (2000): The inescapable images: gender and advertising, Equal Opportunities International, Vol. 19, Iss: 2/3/4, pp. $56-61$.

Monk - Turner, E. et al. (2008.). Who is gazing at whom? A look at how sex is used in magazine advertisements. Journal of Gender Studies, Vol.17, 3, pp. 201 - 209.

Morrison, M., M., Shaffer D., R. (2003): Gender role congruence and self referencing as determinants of advertising effectiveness. Sex Roles, Vol. 49, pp. $265-275$.

Mooij, M. (1998): Global Marketing and Advertising, Sage, Thousand Oaks, CA.

Odekerken-Schröder, G., De Wulf, K, Hofstee, N. (2002): Is gender stereotyping in advertising more prevalent in masculine countries? A cross - national analysis. International Marketing Review, Vol. 19, Iss. 4/5, pp. $408-419$.

Soley, L., Kurzbard, G. (1986): Sex in Advertising: A Comparison of 1964 and 1984 Magazine Advertisements, Journal of Advertising, Vol. 15, Iss. 3, pp. 46-54.

Tavakoli, A., A., Keenan, J., P., Crnjak-Karanovic, B. (2003): Culture and whistleblowing an empirical study of Croatian and United States managers utilizing Hofstede's cultural dimensions. Journal of Business Ethics. Vol. 43, Iss 1/2, pp. 49.

Valls-Fernández F., Martínez, J.M. (2007.). Gender stereotypes in spanish television commercials. Sex Roles, Vol. 56, pp. $691-699$.

Zhang., L., Srisupandit, T., Cartwright, D. (2009): A comparison of gender role portrayals in magazine advertising: The United States,China and Thailand, Management Research News, Vol. 32 Iss. 7, pp.683 - 700. 